\title{
Towards a better way to teach and promote mentally retarded EFL learners' vocabulary learning and retention
}

Rahimi, Masoud

Bu-Ali Sina University, Hamedan, Iran (rahimimasoud87@gmail.com; rahimi.tefl@yahoo.com)

Donyaie, Shadi

Bu-Ali Sina University, Hamedan, Iran (shadidonyaie@yahoo.com)

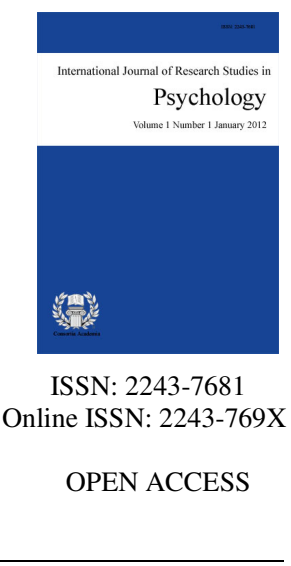

Received: 2 December 2015

\section{Abstract}

The present study aimed at investigating the effect of two vocabulary learning strategies on promoting mentally retarded EFL learners' vocabulary learning in short-term and long-term. To this end, 32 mentally retarded EFL learners (with IQ levels of 50-69) from a mentally retarded institute in Sanandaj, Iran were selected as the participants of the study. First, some English words were selected. Then, the first group was taught through flash cards on which the pictures of the words were depicted. The other group was taught through translation into their $\mathrm{L}_{1}$ which was Kurdish. After the treatments, which took about five weeks, the participants took a vocabulary post-test. Two weeks later another vocabulary post-test was administered to the participants to investigate the long-term effect of the vocabulary learning strategies. The obtained data were analysed through running two independent samples t-test analyses. The results showed that there was a significant difference between the effectiveness of the two vocabulary learning strategies. The group that learned vocabulary via pictures outperformed the other group in both post-tests.

Keywords: vocabulary learning strategies; mentally retarded EFL learners 


\section{Towards a better way to teach and promote mentally retarded EFL learners' vocabulary learning and retention}

\section{Introduction}

Vocabulary learning is a basic task in second language study. Proficiency of language skills such as reading, listening, speaking, and writing all builds on vocabulary knowledge (Zhang \& Li, 2011). There is no doubt that vocabulary is a crucial component of language proficiency. It provides a base for how well learners speak, listen, read, and write. For gaining new words, leaners often achieve less than their potential and may be discouraged from making use of learning opportunities around them such as listening to the radio or watching television (Richards \& Renandya, 2002).

In other words, one cannot learn a language without vocabulary even though there are some teachers who believe that vocabulary does not need to be actively taught (Kang, 1995) and too little is known about the relationship between different aspects of word knowledge (Vermeer, 2001). Krashen (1989) describes learners' interest in vocabulary by the fact that they carry a dictionary more often than a grammar book. Additionally, learners use various strategies to find the meaning of new words to retain them in long-term memory, to retrieve them at will, and to use them in oral or written mode (Catalan, 2003). Moreover, lack of knowledge of academic words impedes the natural process of learning (Carlo et al., 2004), and lack of vocabulary knowledge is frequently mentioned by teachers as a problem (Cameron, 2002). On the other hand, learners have different cognitive approaches to learning vocabulary such as picture, picturing the words spelled out, reacting to the sound of the word, and using dictionary (Cohen \& Aphek, 1980).

Learning vocabulary also occurs among mentally retarded EFL learners, although in learning vocabulary the mentally retarded students need more efforts than normal students to help them remember the words (Dini, Rahmah, \& Harawatti, 2013). Several methods have been used to teach vocabulary skills to mentally retarded children. These can be broadly categorised into four general approaches; those using whole words, phonics, modified alphabets, and programmed instruction and different techniques. In whole words technique high-frequency words are taught by pairing them with pictures (Singh \& Singh, 1986). The present study tried to find out the possible difference between two vocabulary strategies in promoting mentally retarded EFL learners' vocabulary learning.

\subsection{Vocabulary learning}

Definition of learning a word depends crucially on how a word is remembered (Carter \& Nunan, 2001). On the other hand, Linse and Nunan (2006, p. 121) state that "vocabulary is the collection of words that an individual knows". The area of vocabulary in academic texts has drawn the attention of researchers providing new insights and understanding of vocabulary knowledge (Akbarian, 2010a). In recent decades, in order to define what it means to know a word, second language vocabulary researchers have proposed different frameworks. Most researchers agree that vocabulary knowledge is not on all-or-nothing phenomenon but involves degrees of knowledge (Shen, 2009).

Vocabulary knowledge occupies an important position in language learning (Akbarian, 2010b). Knowing a word implies knowing many things about the word such as its literal meaning, its connotations, the syntactic constructions, the morphological options and a rich array of semantic associates such as synonyms and antonyms (August, Carlo, Snow, \& Dressler, 2005). Schmitt (2000) stated that the six frequently used strategies were: using a bilingual dictionary, guessing from textual context, asking classmates for meaning, verbal repetition, written repetition, and studying the spelling. In picture learning the learners can often guess an unfamiliar word by looking at the picture associated with the text. For proficient learners pictures may lead to a better 
A better way to teach and promote mentally retarded EFL learners' vocabulary learning and retention comprehension of the written material, however excessive reliance on picture may hinder the beginning learners' development (Singh \& Singh, 1986).

Dini et al. (2013) conducted a study to improve mentally retarded students' vocabulary mastery. The students were in eighth grade. The results indicated that visual, auditory, kinesthetic and tactile method could improve mentally retarded students' vocabulary mastery. Additionally, (Scott \& Greenfield, 1991) conducted a study in order to compare mentally retarded EFL learners and normally achieving students. The students were asked to (a) describe similarities and differences among exemplars of 12 different categories, (b) identify the categories, and (c) name the exemplars. In this study comparisons yielded large, consistent differences between the mildly retarded and their normally achieving chorological age matches.

Vitale and Romance (2012) found that multi-part instructional strategy could promote grade 4 students' vocabulary knowledge. They further found that the learners could generate greater numbers of words with similar meanings that could be substituted for novel words. While, Markel, Major, and Pelletier (2012) indicated that family factors such as parental education and sibling status significantly promoted children's vocabulary skills. Furthermore, they revealed that vocabulary skills could predict $\mathrm{L}_{1}$ and $\mathrm{L}_{2}$ learners' performance on comprehension tasks. In addition, Heidari-Shahreza, Moinzadeh, and Barati (2014) investigated the relationship between incidental acquisition and retention of non-lexicalised words (i.e. English words which could not be translated with one single word in the learners' $\mathrm{L}_{1}$ ) and culturally-loaded words (i.e. English words with significantly-different cultural connotations). Ninety EFL learners took part in the study. The results indicated that non-lexicalised and culturally-loaded words were semantically different. The results also indicated that both groups of words caused extra difficulty for EFL learners.

\subsection{Mentally retarded EFL learners}

The definition of mental retardation has always been a continuous process (Wehmeyer, 2003). There are many different definitions for mental retardation but the one presented by American Association on mental retardation is, "mental retardation is a level of general intelligence function which is considerably lower than average level and causes deficiencies in the child's adaptive behaviour" (Shea, 2006, pp. 262-270, as cited in Alavi, Savoji, \& Forogh, 2013). Mental retardation refers to substantial limitations in present functioning. It is characterised by sub-average intellectual functioning and it is a state in which functioning is impaired in certain specific ways. The 2002 Manual of the American Psychological Association defines mental retardation as a disability characterised by significant limitations both in intellectual function and in adaptive behaviour (Wehmeyer, 2003).

Mental retardation varies in severity; there is mild retardation, moderate retardation, severe retardation and profound retardation (Dini et al., 2013). Most of the people who are recognised as mentally retarded are classified as mild retarded. These children faced many mental and behavioural problems including inability in learning, personality problems and deficiency in adaptive behaviour (Alavi et al., 2013). Gersten and Maggs (1982) conducted a study to explore the long term effects over a five-year period of direct instruction of language and reading on a sample of 12 pre-adolescent students with IQ's in the low moderate range. Two evaluations in norm-referenced design and criterion-referenced design were conducted. The findings revealed a significant gain beyond the effect. Additionally, Stanovish (1985) conducted a study to investigate mentally-retarded EFL learners' reading progress. The findings generalised to mild mental retardation, it suggested that the reading progress of some mentally retarded children could keep pace with some higher IQ peers who were labeled learning disabled.

In another attempt by Sperber, Davies, and McCauley (1976), they investigated retarded individuals' knowledge of conceptual categories as reflected by semantic priming effects. In the first study, retarded EFL learners were shown two pictures, one picture at a time, and asked to name each picture as rapidly and correctly as possible. The pictures in each group were objects that were either categorically related or unrelated. The major 
Rahimi, M., \& Donyaie, S.

finding was that second pictures in related groups were named significantly faster than those in unrelated groups. The analyses indicated that while performance on both tasks varied with intelligence, neither intelligence nor category usage correlated with the magnitude of the priming effect and retarded and non-retarded adolescent indicated equivalent facilitation of picture naming when the picture was preceded by the name of its superordinate category.

\subsection{Purpose of the study}

The importance of vocabulary learning in itself is emphasised in the field. The present study focused on the vocabulary learning in order to promote mentally retarded EFL learners' vocabulary learning and retention in short and long term. The mentally retarded EFL learners' vocabulary learning has not been given the attention it deserves in practical education including $\mathrm{L}_{2}$ education. Different vocabulary strategies learning could be appealing to educational system, looking to promote mentally retarded EFL learners' foreign language learning. Additionally, familiarising EFL/ESL teachers of mentally retarded EFL learners with better vocabulary learning strategies lead to better organising the students' process of learning. The following research questions were addressed in the present study:

$>$ Is there any significant difference between the two vocabulary learning strategies in promoting mentally retarded EFL learners' vocabulary learning in short-term?

$>$ Is there any significant difference between the two vocabulary learning strategies in promoting mentally retarded EFL learners' vocabulary learning in long-term?

\section{Methodology}

\subsection{Participants}

Thirty-two mentally retarded EFL learners were selected as the participants of the study. They were all female and their age varied from 15 to 17. They were selected based on convenience sampling in an exceptional school in Sanandaj, Iran. The native language of participants was Kurdish and they were all mild mentally retarded of 50-69 IQ.

\subsection{Materials and Instruments}

The present study aimed at investigating the difference between two vocabulary learning strategies in promoting mentally retarded EFL learners. To this end, two tests were developed by the researchers. The two tests were piloted with 15 participants and the results of factor analysis showed acceptable validity. Furthermore, the instruments showed acceptable reliability. One of the tests was conducted immediately after the treatment and another test was conducted two weeks later in order to investigate short-term and long-term differences between the two vocabulary strategies in promoting mentally retarded EFL learners' vocabulary learning.

\subsection{Procedures}

To address the aim of the study, a total of 32 female mentally retarded EFL learners who were in two separate classes participated in the study. Firstly 20 simple English vocabularies were selected. The first group was taught through flash cards which indicate the picture of the vocabularies and the other group was taught through translation into their $\mathrm{L}_{1}$ which was Kurdish. Teaching vocabularies took 5 weeks, then a test developed by the researchers was conducted in order to investigate the short-term differences between the two groups regarding vocabulary learning, another test was conducted two weeks later in order to investigate the difference between the two groups regarding vocabulary learning in long-term. The results were analysed and the normality of the two groups' scores were delved into. The results were analysed through running independent samples 
A better way to teach and promote mentally retarded EFL learners' vocabulary learning and retention t-tests.

\section{Results and Discussion}

Having collected the data by conducting post-tests, the researchers tried to analyse the data through two independent samples t-tests.

Research question 1: Is there any significant difference between the two vocabulary learning strategies in promoting mentally retarded EFL learners' vocabulary learning in short-term?

A test of normality was run to investigate whether the data was normal or not. The results are shown in Table 1.

\section{Table 1}

The Results of the Tests of Normality, Investigating the Normality of the Data

\begin{tabular}{llccc}
\hline & \multicolumn{3}{c}{ group } & Kolmogorov-Smirnov \\
\cline { 3 - 5 } & Picture-group & Statistic & df & Sig. \\
\hline \multirow{2}{*}{ Post-test 1} & Translation-group & .158 & 16 & .200 \\
& & .169 & 16 & .200 \\
\hline
\end{tabular}

To investigate whether there is any significant difference between the two vocabulary learning strategies in promoting mentally retarded EFL learners' vocabulary learning in short-term an independent samples t-test was run. The results for the first research question are shown in Table 2 and 3.

\section{Table 2}

The Results of Descriptive Statistics, Investigating the Difference between the Two Vocabulary Learning Strategies in Mentally Retarded EFL Learners' Vocabulary Learning in Short Term

\begin{tabular}{lllccc}
\hline & \multicolumn{1}{c}{ group } & $\mathrm{N}$ & Mean & Std. Deviation & Std. Error Mean \\
\hline \multirow{2}{*}{ Post-test 1 } & Picture-group & 16 & 12.25 & 3.088 & .772 \\
& Translation-group & 16 & 9.81 & 2.713 & .678 \\
\hline
\end{tabular}

As is shown in Table 2, the mean of picture-group is 12.25 and the mean of the other group is 9.81 .

\section{Table 3}

Results of Independent Samples T-test for Investigating the Difference between the Two Vocabulary Learning Strategies in Short Term

\begin{tabular}{|c|c|c|c|c|c|c|c|c|c|c|}
\hline & & $\begin{array}{r}\text { Lev } \\
\text { Tes } \\
\text { Equa } \\
\text { Vari }\end{array}$ & $\begin{array}{l}\text { ne's } \\
\text { for } \\
\text { ty of } \\
\text { nces }\end{array}$ & & & T-tes & st for Equa & lity of Mean & & \\
\hline & & $\mathrm{F}$ & Sig. & $\mathrm{t}$ & df & $\begin{array}{l}\text { Sig. } \\
\text { (2-taile }\end{array}$ & $\begin{array}{c}\text { Mean } \\
\text { Difference }\end{array}$ & $\begin{array}{l}\text { Std. Error } \\
\text { Difference }\end{array}$ & $\begin{array}{r}95 \% \mathrm{C} \\
\text { Interv } \\
\text { Dif }\end{array}$ & $\begin{array}{l}\text { fidence } \\
\text { of the } \\
\text { ence }\end{array}$ \\
\hline & & & & & & & & & Lower & Upper \\
\hline Dost toct? & $\begin{array}{l}\text { Equal variances } \\
\text { assumed }\end{array}$ & .470 & .498 & 2.372 & 30 & .024 & 2.438 & 1.028 & .339 & 4.536 \\
\hline Post-test 2 & $\begin{array}{l}\text { Equal variances } \\
\text { not assumed }\end{array}$ & & & 2.372 & 29.513 & .024 & 2.438 & 1.028 & .337 & 4.388 \\
\hline
\end{tabular}

As shown in Table 3, the difference between the two groups is significant and picture-group outperforms the translation-group in short term.

Research question 2: Is there any significant difference between the two vocabulary learning strategies in 
Rahimi, M., \& Donyaie, S.

promoting mentally retarded EFL learners' vocabulary learning in long-term?

A test of normality was run to investigate whether the data was normal or not. The results are shown in Table 4.

Table 4

The Results of the Tests of Normality, Investigating the Normality of the Data

\begin{tabular}{|c|c|c|c|c|}
\hline & \multirow[b]{2}{*}{ group } & \multicolumn{3}{|c|}{ Kolmogorov-Smirnov $^{a}$} \\
\hline & & Statistic & $\mathrm{df}$ & Sig. \\
\hline \multirow{2}{*}{ Post-test 2} & Picture-group & .197 & 16 & .096 \\
\hline & Translation-group & .189 & 16 & .128 \\
\hline
\end{tabular}

To investigate whether or not there is a difference between the two vocabulary learning strategies in long-term an independent samples t-test was run. The results for the second question are shown in Tables 5 and 6.

\section{Table 5}

The results of Descriptive Statistics, Investigating the Difference between the Two Vocabulary Learning Strategies in Mentally Retarded EFL Learners' Vocabulary Learning in Long Term

\begin{tabular}{cllccc}
\hline & \multicolumn{1}{c}{ group } & N & Mean & Std. Deviation & Std. Error Mean \\
\hline \multirow{2}{*}{ Post-test 2 } & Picture-group & 16 & 13.56 & 2.780 & .695 \\
& Translation-group & 16 & 11.19 & 2.509 & .627 \\
\hline
\end{tabular}

As shown in Table 5, the mean of the picture-group is 13.56 and the mean of the other group is 11.19.

\section{Table 6}

Result of Independent Samples T-test for Investigating the Difference between the Two Vocabulary Learning Strategies in Long Term

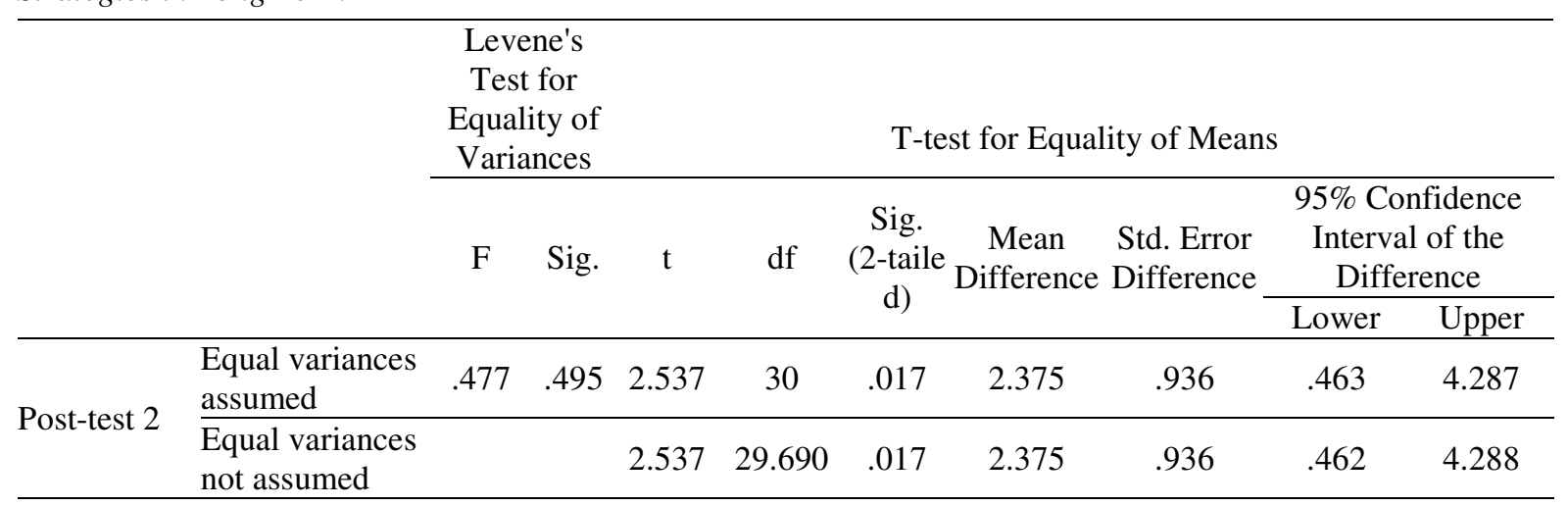

As shown in Tables 5 and 6, the second post-test group difference is significant regarding the two different vocabulary learning strategies. The results of the two tables further indicate that the picture-group outperforms the translation-group in long term.

The present study sought to investigate the possible difference between two vocabulary learning strategies in promoting mentally retarded EFL learners' vocabulary learning and retention. The results as can be seen from Table 3, the group that learned vocabularies through pictures outperformed their counterpart that is the other group that learned vocabularies through translation into their $\mathrm{L}_{1}$ in short-term. As can be seen from Table 6, the results of the second test indicate that the first group (learning through pictures) outperformed the other group. Therefore the results showed that the picture vocabulary learning strategy was more effective in promoting mentally retarded EFL learners. 
A better way to teach and promote mentally retarded EFL learners' vocabulary learning and retention

One hypothesis for limited success with severely mentally retarded individuals posits that these learners lack the metacognitive control abilities with which to sensibly organise incoming verbal language stimuli (Luftig, 1982). The results of the present study about mentally retarded EFL learners' vocabulary learning may in particular aspects be related to Scott and Greenfield (1991) as has been argued that for a screening instrument to effectively detect the mildly cognitively impaired, it must require the child to engage in active cognitive processing of higher order information only by pushing the cognitive capacity of these children. In the present study, in the picture learning the mentally retarded EFL learners acquire vocabularies better because it seems as if they engage in the learning process. Kang (1995) asserted that translation into native language which has been predominantly used as a way of presenting a meaning has a serious drawback which has been the major target of criticism by language researchers. The results of Kang are not in line with the present study since the participants of the present study are able to associate a spoken word with its picture and remember this association.

World Health Organization (1996) pointed out that mild mentally retarded EFL learners learned with some delay however they could be helped by educational design. As the results showed the first group that learned vocabularies with pictures outperformed the other group. The results of this study is not in line with Luftig (1982) who stated that no program has been reported which indicated that the mentally retarded pupils increased their vocabularies generalised to new language situations. Luftig (1982) referred to Kahn (1981) who compared speech training and sign language training methods in the language learning of severely mentally retarded children and found that while all of the children in the signing condition learned some signs, only half of them in the speech condition learned some words. It may be because as it was indicated in the present study mentally retarded EFL learners learn better with no speech methods.

\section{Conclusions and implications}

The present study set out to investigate the effects of two vocabulary learning strategies on mentally retarded EFL learners' vocabulary learning and retention. The results of two independent samples t-test of the study can be summarised as follows:

The mentally retarded EFL learners of the study in both post-tests showed significant differences of two vocabulary learning strategies, the group that learned vocabularies through pictures outperformed their counterparts in the other group. The findings of the study might provide some implications for mentally retarded EFL learners. It seems that they should be encouraged to adopt appropriate strategies. The findings might be also fruitful for instructors and material developers of mentally retarded EFL learners. They are recommended to pay more attention to the role of vocabulary strategies that are most helpful for those learners.

\section{References}

Akbarian, I. (2010a). The comparative development of vocabulary breadth and depth, and academic vocabulary for ESP/EAP learners. Iranian Journal of Applied Linguistics, 1-22.

Akbarian, I. (2010b). The relationship between vocabulary size and depth for ESP/EAP learners. System, 38(3), 391-401. http://dx.doi.org/10.1016/j.system.2010.06.013

Alavi, Z., Savoji, A., \& Forogh, A. (2013). The effect of social skills training on aggression of mild mentally retarded children. Procedia-Social and Behavioral Sciences, 84, 1166-1170. http://dx.doi.org/10.1016/j.sbspro.2013.06.720

August, D., Carlo, M., Snow, C., \& Dressler, C. (2005). The critical role of vocabulary development for English language learners. Learning Disabilities Research \& Practice, 20, 50-57. http://dx.doi.org/10.1111/j.1540-5826.2005.00120.x

Cameron, L. (2002). Measuring vocabulary size in English as an additional language. Language Teaching Research, 6(2), 145-173. http://dx.doi.org/10.1191/1362168802lr103oa

Carlo, M. S., August, D., McLaughlin, B., Snow, C. E., Dressler, C., Lippman, D. N., ... \& White, C. E. (2004). Closing the gap: Addressing the vocabulary needs of English-language learners in bilingual and 
Rahimi, M., \& Donyaie, S.

mainstream classrooms. Reading Research Quarterly, 39(2), 188-215. http://dx.doi.org/10.1598/RRQ.39.2.3

Carter, R., \& Nunan, D. (2001). The cambridge guide to teaching English to speakers of other languages. Cambridge: Cambridge University Press. http://dx.doi.org/10.1017/CBO9780511667206

Catalan, R. (2003). Sex differences in L2 vocabulary learning strategies. International Journal of Applied Linguistics, 13, 54-78. http://dx.doi.org/10.1111/1473-4192.00037

Cohen, A., \& Aphek, E. (1980). Retention of second lanaguge vocabulary over time. System, 8, 221-235. http://dx.doi.org/10.1016/0346-251X(80)90004-4

Dini, N., Rahmah, M., \& Harawatti, A. (2013). Improving mentally retarded students' vocabulary mastery through visual, auditory, kinesthetic and tactile (VAKT) method.

Gersten, R., \& Maggs, A. (1982). Teaching the general case to moderately retarded children evaluation of a five year project. Analysis Attd Intervention in Doelopmental Disabilities, 2(4), 329-343. http://dx.doi.org/10.1016/0270-4684(82)90028-3

Heidari-Shahreza, M. A., Moinzadeh, A., \& Barati, H. (2014). A comparative investigation into effects of L1 lexicalization and cultural loadedness on incidental vocabulary acquisition and retention. International Journal of Research Studies in Language Learning, 3(5), 83-96. http://dx.doi.org/10.5861/ijrsll.2014.698

Kahn, J. V. (1981). A comparison of sign and verbal language training with nonverbal retarded children. Journal of Speech, Language, and Hearing Research, 24(1), 113-119. http://dx.doi.org/10.1044/jshr.2401.113

Kang, S. (1995). The effects of a context-embedded approach to second-language vocabulary learning. System, 23, 43-55. http://dx.doi.org/10.1016/0346-251X(94)00051-7

Krashen, S. (1989). We acquire vocabulary and spelling by reading: additional evidence for the input hypothesis. The Modern Language Journal, 73, 440-464. http://dx.doi.org/10.1111/j.1540-4781.1989.tb05325.x

Linse, C., \& Nunan, D. (2006). Practical English language teaching young learners. New York.

Luftig, R. (1982). Increasing probability of sign language learning by severely mentally retarded individuals: A discussion of learner, sign production, and linguistic variables. Applied Research in Mental Retardation, 3, 81-97. http://dx.doi.org/10.1016/0270-3092(82)90060-1

Markel, C., Major, A., \& Pelletier, J. (2012). Relations among children's theory of mind, family factors, language development, and story comprehension in L1 and L2 preschoolers. International Journal of Research Studies in Psychology, 2(2), 15-32.

Richards, J., \& Renandya, W. (2002). Methodology in language teaching. Cambridge Press. http://dx.doi.org/10.1017/cbo9780511667190

Schmitt, N. (2000). Vocabulary in language teaching. Cambridge: Cambridge University Press.

Scott, M., \& Greenfield, D. (1991). The screening potential of a taxonomic information task for the detection of learning disabled and mildly retarded children. Journal of Applied Developmental Psychology, 12, 429-466. http://dx.doi.org/10.1016/0193-3973(91)90019-Z

Shen, Z. (2009). The roles of depth and breadth of vocabulary knowledge in EFL reading performance. Asian Social Science, 4(12), 135-137. http://dx.doi.org/10.5539/ass.v4n12p135

Singh, N., \& Singh, J. (1986). Reading acquisition and remediation in the mentally retarded. International Review of Research in Metal Retardation, 14, 165-199. http://dx.doi.org/10.1016/S0074-7750(08)60078-6

Sperber, R., Davies, D., \& McCauley, C. (1976). Reassessment of category knowledge in retarded individuals. American Journal of Mental Deficiency, 81, 227-234.

Stanovish, K. (1985). Cognitive determinants of reading in mentally retarded individuals. International review of research in mental retardation, 13, 181-214. http://dx.doi.org/10.1016/S0074-7750(08)60236-0

Vermeer, A. (2001). Breadth and depth of vocabulary in relation to L1/L2 acquisition and frequency of input. Applied Psycholinguistics, 22, 217-234. http://dx.doi.org/10.1017/S0142716401002041

Vitale, M. R., \& Romance, N. R. (2012). A research-based strategy for inductively accelerating vocabulary acquisition of at-risk students in Grade 4. International Journal of Research Studies in Language Learning, 1(2), 33-46. http://dx.doi.org/10.5861/ijrsll.2012.v1i2.73 
A better way to teach and promote mentally retarded EFL learners' vocabulary learning and retention

Wehmeyer, M. (2003). Defining mental retardation and ensuring access to the general curriculum. Education and Training in Developmental Disabilities, 38(3), 271-282.

World Health Organization. (1996). ICD-10 guide for mental retardation. Geneva, Switzerland.

Zhang, B., \& Li, C. (2011). Classification of L2 vocabulary learning strategies: Evidence from exploratory and confirmatory factor analyses. RELC journal, 42(2), 141-154.

ttp://dx.doi.org/10.1177/0033688211405180 
Rahimi, M., \& Donyaie, S. 